\title{
In vivo antitrypanosomal activities of Acacia nilotica stem bark methanol extract in Wistar rats infected with Trypanosoma brucei brucei
}

\author{
Junaidu Isah Goronyo ${ }^{1 *}$, Yakubu Kokori Enevene Ibrahim ${ }^{1}$, Babajide Akinyele Tytler ${ }^{1}$, \\ Mujahid Hussaini²
}

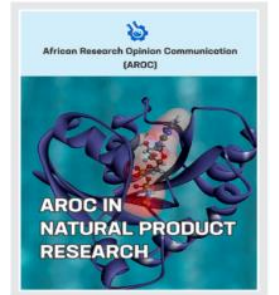

${ }^{1}$ Department of Pharmaceutical Microbiology, Ahmadu Bello University, Zaria, Nigeria. 2Department of Microbiology, Umaru Musa Yar'adua University, Katsina, Nigeria.

Corresponding author: Junaidu Isah Goronyo: junaiduisahgoronyo@gmail.com Received: 26 January 2022, Revised: 23 February 2022, Published: 01 March 2022

https://doi.org/10.53858/arocnpr02012127

Background: Trypanosomiasis is a disease of vertebral animals caused by parasitic protozoa of the genus Trypanosoma. It is one of the neglected tropical diseases (NTDs) affecting about 36 countries of Sub-saharan Africa, threatening more than 60 million people and 70 million animals. Chemotherapy is the major means of controlling African trypanosomiasis is limited by rapid drug resistance, toxicity and high cost. There is an urgent need for therapeutic agents that are effective, affordable, and accessible to the rural poor people in Africa who are greatly affected by the disease. This study aimed to determine the in vivo effect of stem bark methanol extract of Acacia nilotica ( . nilotica) on experimental Trypanosoma brucei brucei infection in Wistar rats. Methods: Phytochemical analysis, and $L_{50}$ determination were carried out using standard procedures. Three (3) days pre-patent period was observed after inoculating the rats with the parasite. Parasitemia was monitored daily while the Parked Cell Volume (PCV) was determined at one-day intervals during the infection course. Results: The phytochemical analysis showed the presence of carbohydrates, steroid/triterpenes, saponin, alkaloid, flavonoid, tannin, glycosides, and anthraquinones. The toxicity of the stem bark methanol extract was tolerable at $1200 \mathrm{mg} / \mathrm{kg}$ body weight. Methanol extract of $A$. nilotica (stem bark) showed promising curative potential in vivo against Trypanosoma brucei brucei at 300,400 and $500 \mathrm{mg} / \mathrm{kg}$ body weight. These doses completely cured the experimental T.b.b infection in Wistar rats after 3 days of treatment. Significant reduction $(p<0.05)$ in the parasite burden confirmed by the absence of anaemia (PCV $48.1 \% \pm 1.5 \%$ and $46.4 \% \pm 1.3 \%$ respectively) was observed when compared with the "infected but not treated" control group (normal saline group). Conclusion: Based on these observations, it was therefore deduced that the methanol extract of Acacia nilotica stem bark extract possessed the active ingredient that cures experimental $T$. brucei brucei infections in Wistar rats.

Keyword: Trypanosoma brucei brucei; A. nilotica; Stem bark; anti-trypanosomal; in vivo; crude methanol extract Citations: Goronyo I.J., Ibrahim Y.K.E., Tytler B. A., and Mujahid, H. (2022). In vivo antitrypanosomal activities of Acacia nilotica stem bark methanol extract in Wistar rats infected with Trypanosoma brucei brucei. AROC in Natural Products Research, 2(1);21-27, https://doi.org/10.53858/arocnpr02012127

\subsection{Introduction}

Trypanosoma brucei brucei is a protozoan of the genus Trypanosoma that causes trypanosomiasis in cattles and other domestic animals by infecting their blood plasma [1]. This parasite is transmitted by tsetse flies of the family Glossinidae [2]. Susceptible animals when infected become weak, emaciated, and reproductively breeding animals may abort and become infertile [1]. The Trypanosomes, Trypanosoma vivax, Trypanosoma congolense and Trypanosoma brucei brucei are the main species responsible for African Animal Trypanosomiasis (AAT) called Nagana in West Africa. Human African Trypanosomiasis (HAT) or sleeping sickness is a disease caused by two subspecies of Trypanosome brucei, i.e. T. brucei gambiense and T. brucei rhodesiense. Surra and Dourine are caused by the other Trypanosoma species T. evansi and $T$. equiperdum respectively. Sleeping sickness occurs in 36 sub-Saharan African countries where there are tsetse flies that transmit the disease [3].

In Nigeria, the disease is prevalent and the wide distribution of the disease is attributed to the abundance of its biological and mechanical transmitting vectors which are tsetse flies and biting flies, respectively [4]. It affects human and livestock production causing significant losses which range from a decrease in milk production to death [4]. All warmblooded animals including wildlife species have been implicated in the transmission cycle of the disease. Tsetse flies cover approximately $80 \%$ of the landmass in Nigeria, hence AAT continues to thrive, and losses 
incurred have not been reduced [5]. However, it seems to be re-emerging as a significant livestock disease and extending to areas that were previously designated as tsetse fly- free zones [6].

The current chemotherapy of Trypanosomosis relies on drugs which were been used for donkey years and are expensive with toxic side effects and many studies have shown the emergence of strains that develop resistance to these drugs [7]. In view of these the development of new inexpensive, effective drugs in the treatment of Trypanosomiasis is urgently required to control the disease. However, it has been observed that natural products obtained from plants and the recent discovery of novel drugs such as artemisinin, atropine, digitoxin, digoxin, emetine, pilocarpine, quabain, quinidine, quinine, reserpine, vinblastine, vincristine, etc., from medicinal plants implies that vast potential still exists for the production of numerous more novel drugs [8]. Consequently, the area of ethnopharmacology of medicinal plants has attracted increasing attention in new drugs research and development [9]. This is the main reason why this research was designed to study the Antitrypanosomal properties of the components of Stem bark extract of Acacia nilotica plant.

Acacia nilotica (common name: Gum Arabic tree) is commonly found in Guinea and Sudan Savannah vegetation in Nigeria. It is locally called Bagaruwa in Hausa, Gaude in Fulfulde and Kangar in Kanuri. The plant is widely used in traditional medicine in Africa, it has been found to possess significant antimicrobial activity, antioxidant, antidiarrhoeal, anticancer, antimutagenic properties, anthelmintic activity, antiplatelet aggregatory activity and vasoconstrictor among others [10]. The aim of this study was to determine the in vivo anti-trypanosomal effect of Acacia nilotica stem bark methanol extract in Wistar rats infected with Trypanosoma brucei brucei.

\subsection{Materials and Methods}

This research is a further study on the authors' previous work carried out (on the phytochemical screening and acute toxicity studies on Acacia nilotica stem bark methanol extract) and re-described in sections (2.1 - 2.8, 3.1, 3.2 and 4.0) of this paper.

\subsection{Animal ethical clearance}

An application was submitted to the Animal Right Ethical Committee of Ahmad Bello University, Zaria and clearance/approval (Reference number: ABUCAU/2020/015) was granted upon satisfying all conditions.

\subsection{Sources of plant material and identification}

Fresh stem bark of Acacia nilotica (Linn) plant was obtained from Usmanu Danfodio University Sokoto (UDUS), Sokoto State, North-West Nigeria, between December 2019 and January 2020. The plant sample was identified at the Herbarium unit of the Department of Botany, Faculty of Life Sciences, Ahmadu Bello University Zaria, where a Voucher specimen number of ABU014634 was given and deposited.

\subsection{Plant preparation}

The collected stem bark was washed with tap water to remove dirt and dried under shade. The dried materials were ground using pestle and mortar. Eight hundred grams $(800 \mathrm{~g})$ of the ground stem bark was weighed and stored in a clean tied-up polythene bag at room temperature until required.

\subsection{Stem bark extraction}

Standard procedures were used for the extraction of the plant materials. 500 grams of the ground stem bark was used for extraction with methanol using a Soxhlet apparatus for 24 hours. The liquid extract was concentrated to dryness under rotary evaporator to remove the solvent for 12 hours. The recovered extract was weighed and transferred to sterile universal bottle which was kept in the refrigerator until required.

\subsection{Phytochemical screening}

Ten (10) grams of crude stem bark methanol extract was used to evaluate the presence of some active Phyto-constituents like carbohydrates, steroids, triterpenes, cardiac glycosides, saponin, tannin, flavonoid, alkaloid, and anthracenes, using methods described by Evans [11].

\subsection{Test parasite}

An isolate of Trypanosoma brucei brucei was obtained from the Department of Veterinary Parasitology and Entomology Ahmadu Bello University Zaria and maintained in the laboratory by serial passage in rats. The culture was confirmed microscopically.

\subsection{Experimental animals}

A total of 100 Wistar rats of both sexes weighing 100 - 120 grams were purchased from the animal house of the Department of Pharmacology, Faculty of Pharmaceutical Science, Ahmadu Bello University, Zaria. The experiment was conducted in compliance with the internationally accepted principle for laboratory animal use and care as contained in Organisation for Economic Cooperation and Development (OECD) guidelines on animal use protocol. The animals were maintained on commercially prepared feed and housed in disinfected cages for one week to acclimatize prior to the commencement of the experiment. The experiment was conducted at the Protozoology laboratory of the Department of Veterinary Parasitology and Entomology, Faculty of Veterinary Medicine, Ahmadu Bello University, Zaria. 


\subsection{Acute Toxicity Studies/Determination of LD 50}

Before experimenting with the animals, normal females, nulliparous and non-pregnant were randomly selected and grouped into five groups $(n=4)$ and then kept in their cages for 7 days prior to dosing to allow acclimatization to the laboratory conditions. All groups of the rats fasted overnight prior to administration. Following the fasting period, all animals were weighed, and the doses were calculated based on their body weight. The animals were given $80 \%$ methanol stem bark crude extracts (prepared in distilled water) orally at different doses of 600,800, 1000 and 1200 $\mathrm{mg}$ per kilogram body weight $\left(\mathrm{kg}^{-1} \mathrm{bw}\right)$ respectively while distilled water was given to fifth group (control group). After the administration, the animals were kept under close observation continuously for 1 hour and intermittently for 4 hours and thereafter once every 24 hours for the next 2 days. During this study period, clinical observations were made for mortality, behavioral changes, unnecessary noises and any other abnormalities and their weight were measured.

The $\mathrm{LD}_{50}$ was calculated using the formula:

$\operatorname{LD} 50=\sqrt{(D o \times D 100)} \quad$ Where:

$D_{0}=$ Highest dose that gave no mortality and $D_{100}=$ Lowest dose that produced mortality [12].

\subsection{Inoculation of experimental rats with test organism isolate}

A $3 \mathrm{ml}$ of blood was collected by cardiac puncture with EDTA coated syringe from heavily infected rats followed by dilution with normal saline to serve as inoculum. Healthy rats were infected intraperitoneally with $0.2 \mathrm{ml}$ of the inoculum containing about $10^{6}$ trypanosome cells. Infection was monitored daily by microscopic examination of blood samples taken from tails of the infected animals. The degree of Parasitaemia was determined using the rapid matching method [13].

\subsection{Treatment of the infected rats with crude stem bark methanol extract}

To determine the bioactivity of the crude methanol extract, initial experiments were carried out. On day 3 post-infection $(\mathrm{PI})$, three groups of rats $(1-3)$ were orally administered with the extract at doses of 300, 400 , and $500 \mathrm{mg}$ per kilogram body weight $\left(\mathrm{kg}^{-1} \mathrm{bw}\right)$ respectively for 7 days. The fourth group formed the negative control (infected but not treated), while the infected and treated with $3.5 \mathrm{mgkg}-1 \mathrm{bw}$ of the standard drug diminazene (fifth group) served as the positive control [14].

\subsection{Determination of parasitaemia}

Parasite count was monitored daily in the infected groups and determined microscopically at 400 magnification using the "Rapid Matching" method of Herbert and Lumsden, [15]. Briefly, this involved microscopic counting of parasites per field in pure blood or blood appropriately diluted with phosphatebuffered saline (PBS, pH 7.4). Logarithmic values of these counts obtained by matching with the table of Herbert and Lumsden is converted to antilog to provide an absolute number of trypanosomes per $\mathrm{ml}$ of blood [16]. The pre-patent period was determined when the first $T$. brucei brucei parasite was seen in the blood of the infected animals.

\subsection{Packed Cell Volume (PCV)}

The PCV of the animals from each group were determined on $0,2,4,6,8,10,12$ and 14 days' post-infection by the Microhaematocrit method described by Coles [17]. The blood was directly taken from the ocular vein into heparinized capillary tubes by capillary action to about $75 \%$ of its length. The ends of the tubes were sealed with a flame using a Bunsen burner. The sealed tubes were placed in a microhaematocrit centrifuge, with the sealed ends near the outside rim of the centrifuge (touching the rim). The cover of the centrifuge was tightened to prevent blood spillage and centrifuged for 5 minutes. Thereafter, the capillary tubes were placed in a graphic reader and the packed cell volume (PCV) were directly read in percentage.

\subsection{Statistical Analysis.}

All values were shown as mean values along with their standard deviations ( \pm SD). SPSS software was used to analyze data. Statistical comparisons were carried out by Analysis of Variance (ANOVA), Tukey's multiple comparison test, and $p$ values $<0.05$ were considered significant.

\subsection{Results}

\subsection{Phytochemical compositions}

Table 1 shows the results of Acacia nilotica stem bark preliminary phytochemical analysis. The compounds present include carbohydrate, flavonoid, saponin, alkaloid, cardiac glycosides, triterpenes, unsaturated steroids, Anthraquinones. These compounds were physiologically active phytoconstituents of most medicinal plants possessing great potential for therapeutic and prophylactic uses.

\subsection{Acute toxicity studies}

The Acute Toxicity studies of the showed no evidence of toxicity in Group $1\left(600 \mathrm{mgkg}^{-1}\right)$ and Control group (distilled water). Conversely, there was slight increase in observable toxicity effect in the groups (animals) with increase in the administered dose however, animals fully recovered and regained their activeness after few hours and no single death (Table 2). 
Table 1: Phytochemical constituents present in the methanol crude stem bark extract of A. nilotica.

\begin{tabular}{|l|l|l|l|}
\hline Phytochemicals & Test & Observation & Result \\
\hline Carbohydrate & Molisch & Reddish colour & $\mathbf{+}$ \\
\hline Flavonoid & Sodium hydroxide & Yellow colouration & $\mathbf{+}$ \\
\hline Saponin & Frothing test & Foam formation & $\mathbf{+}$ \\
\hline Alkaloid & Wagner's test & White precipitate & $\mathbf{+}$ \\
\hline Cardiac Glycosides & Keller-killani test & Pale green & $\mathbf{+}$ \\
\hline Triterpenes & Lieberman bucchard & Pink colour & $\mathbf{+}$ \\
\hline Unsaturated steroid & Lieberman bucchard & Blue-green colour & $\mathbf{+}$ \\
\hline Anthraquinones & Bontrager's test & Bright pink colour & $\mathbf{+}$ \\
\hline
\end{tabular}

KEYS: $+=$ present

Table 2: Determination of median lethal dose $\left(L D_{50}\right)$ from crude methanolic stem bark extract of Acacia nilotica.

\begin{tabular}{|c|c|c|c|}
\hline $\begin{array}{l}\text { Group } \\
(n=4)\end{array}$ & $\begin{array}{l}\text { Treated } \\
\text { Dose }\end{array}$ & $\begin{array}{l}\text { Number of Dead } \\
\text { Animal }\end{array}$ & Observation \\
\hline Group 1 & $600 \mathrm{mgkg}^{-1}$ & 0 & No sign of toxicity; animals remain active. \\
\hline Group 2 & $800 \mathrm{mgkg}^{-1}$ & 0 & $\begin{array}{l}\text { Animals remain sluggish for a while and later become normal } \\
\text { again. }\end{array}$ \\
\hline Group 3 & $1000 \mathrm{mgkg}^{-1}$ & 0 & $\begin{array}{l}\text { Breathing was slow, there was the closing of eyes and erection } \\
\text { of fur but animals later recovered fully. }\end{array}$ \\
\hline Group 4 & $1200 \mathrm{mgkg}^{-1}$ & 0 & $\begin{array}{l}\text { Sluggishness, closing of eyes, depressed breathing but later } \\
\text { becomes active after some hours. }\end{array}$ \\
\hline Group 5 & $\begin{array}{l}\text { Distilled } \\
\text { water }\end{array}$ & 0 & No signs of toxicity observed \\
\hline
\end{tabular}

KEY: $n=$ Number of Animal per group

\subsection{Test for Antitrypanosomal activities of stem bark crude methanol extracts}

The crude methanol extract of Acacia nilotica plant was subjected for bioassay to determine its curative effects in rats infected with $T$. brucei brucei. The crude methanol extract of Acacia nilotica at the doses of 300,400 , and $500 \mathrm{mg} / \mathrm{kg}$ bw inhibited the $T$. brucei brucei parasites proliferation (Figure 1), and improve the body packed cell volume of the infected rats (Figure 2) when compared with the group administered with normal saline. In the presence of the antitrypanosomal agents (CME and DMZ), the load (Estimated Marginal Means) of the T. brucei brucei parasites (Figure 1) was indirectly proportional to the Average PCV of the animals observed (Figure 2). There was no positive therapeutic effect observed in groups administered with normal saline.

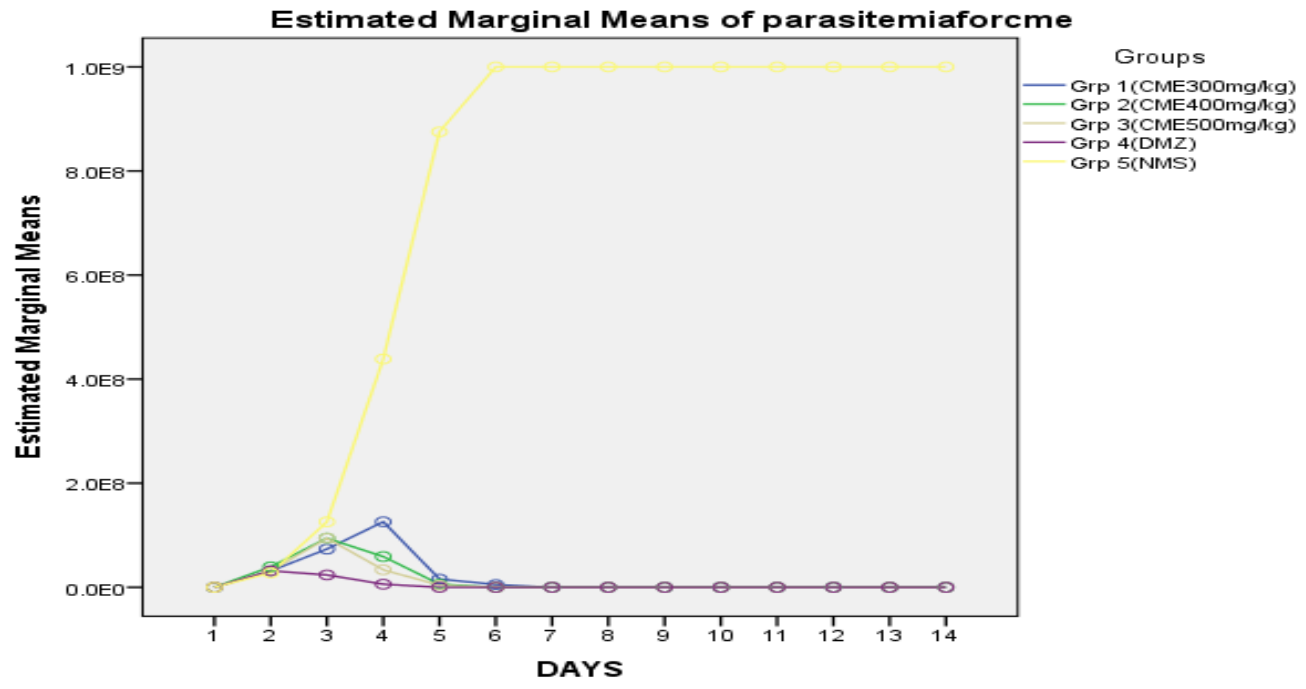

Figure 1: Screening for the antitrypanosomal effects of stem bark crude methanol extract (CME) of $A$. nilotica. Key: $\mathrm{Grp}=$ group, $\mathrm{CME}=$ crude methanol extract, $\mathrm{DMZ}=$ diminazene, $\mathrm{NMS}=$ normal saline 


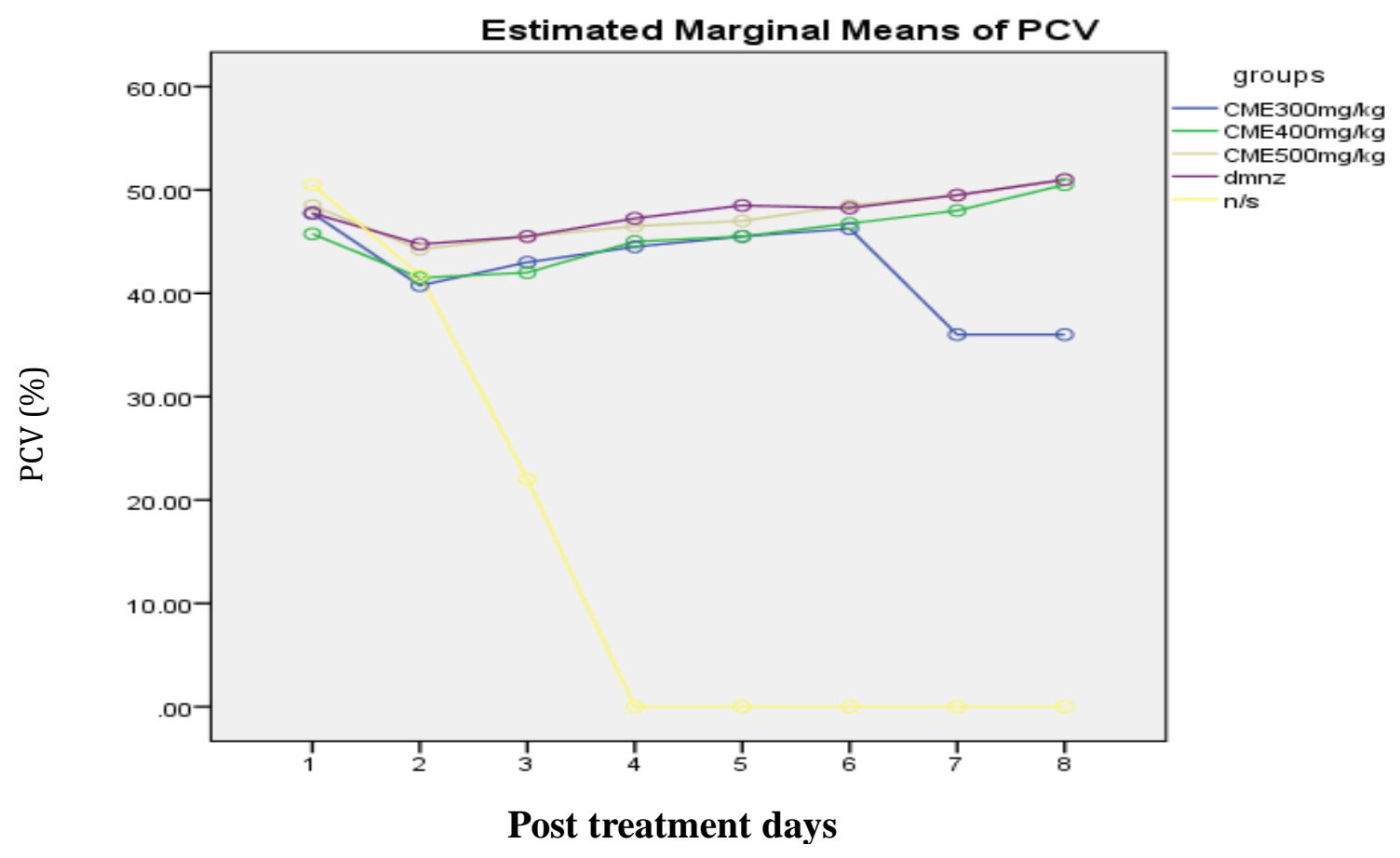

Figure 2: Average parked cell volume of groups of rats (1-5) treated with CME of $A$. nilotica stem bark extract. Key: $\mathrm{Grp}=$ group, $\mathrm{CME}=$ crude methanol extract, $\mathrm{DMZ}=$ diminazene, $\mathrm{n} / \mathrm{s}=$ normal saline

\subsection{Discussion}

The present study evaluated the antitrypanosomal activities of Acacia nilotica stem bark methanol extracts in Wistar rats infected with Trypanosoma brucei brucei. The result of the phytochemical analysis of the crude methanol stem bark extract of $A$. nilotica reveals the presence of carbohydrates, flavonoids, tannins, saponins, alkaloids, cardiac glycosides, anthraquinones, steroids and triterpenes (Table 1). This data supports several other studies that reported similar phytochemical constituents from this plant $[17,18]$.

The report of Abdulhamid and Amar [9] on phytochemical analysis of this plant's leaves also agreed with our findings. Moreover, Jatau and TsokNwok, [14] reported that fruit pods of $A$. nilotica contain the same compounds similar to our result. Anyam et al., [19] reported a similar result from the root methanol extract of this plant. Thus, this proves that different parts (stem, leaves, and fruits) of the plants tend to have similar phytochemical constituents. These phytochemicals are physiologically active compounds possessing great potential for several therapeutic and prophylactic uses/applications [20].

The median lethal dose (LD50) determination/Acute toxicity test assesses the adverse effects that occur within a short time after administration of a single dose of a test substance. The acute toxicity study carried out in this research did not show any toxicity signs and symptoms at 600,800, 1000 and $1200 \mathrm{mg}$ $\mathrm{kg}-1 \mathrm{bw}$. No morbidity or mortality was observed in the treated groups for each dose during the acute toxicity study. As a result, the LD50 of the extract could be greater than $1200 \mathrm{mg} / \mathrm{kg}$ body weight (Table 2). The present results from the acute toxicity study agreed with the study reported by [14] who reported that methanol fruit pod extract of Acacia nilotica was relatively safe at $5000 \mathrm{mg} / \mathrm{kg}$. Therefore, $80 \%$ methanol extract may be considered relatively safe on acute exposure.

The compounds obtained from phytochemical screening are known to be biologically active and thus may have contributed to the observed antitrypanosomal activities in this plant stem bark methanol extract [22]. The stem bark methanol extract at 400 and $500 \mathrm{mg} / \mathrm{kg}$ doses showed a very similar effect as the standard antitrypanosomal agent (diminazene) and cleared all parasites in the infected rats after 5 days of treatment and these rats remain aparasitic for up to 20 days while the Parked Cell Volumes (PCV) mean values remain within the normal range $(43 \%-53 \%)$. This indicates the absence of anaemia which is the major pathological feature of trypanosomiasis which is considered as a pointer of the acute nature of the infection [21]. The PCVof the 
"infected but not treated" control group dropped faster $(48 \%$ to $22 \%)$ compared to the gradual decrease observed in the treated groups. There was a significant statistical difference $(p<.05)$. between the crude methanol extract treated groups and control group (infected but not treated) This agrees with the report of Ogbadoyi et al. [13[ who reported that methanol crude extract of Acacia stem bark at 400 and $500 \mathrm{mg} / \mathrm{kg}$ doses cleared $T$. brucei brucei in mice after 3 days of treatment. Findings from Jatau and Tsok-Nwok, [14], revealed that the methanol extract of fruit pods of this plant exerted a curative effect on Trypanosoma infected rats, after 5 days' treatments. Crude methanolic root extracts of $A$. nilotica demonstrate significant activity against chloroquinesensitive protozoa strain of Plasmodium berghei in mice [7].

Moreover, the plants exhibited dose and timedependent activities, this suggests that the antitrypanosomal effect of the extract is dosedependent, as higher dosage (evidencing a higher PCV value) may mean a higher concentration of the active phytochemical components, which could be responsible for the survival of the rats treated with 400 and $500 \mathrm{mg} / \mathrm{kg} /$ day for 10 days after the experiment was concluded. More specifically, the activities reported on this plant against $T$. brucei brucei may be due to the presence of triterpenes and tannins which were reported to have antiprotozoal activities [6, 23]. Flavonoids and alkaloid compounds were also reported to have antitrypanosomal [24].

\subsection{Conclusion}

The crude methanol extract of Acacia nilotica stem bark was evidenced to entail several bioactive compounds and have shown a very promising and positive anti-trypanosomal effect on $T$. brucei brucei in the experimental rats. Further research on these plant stem back fractions is in progress.

\section{Acknowledgement}

The authors acknowledge the efforts of the Head and staff of the Department of Veterinary Parasitology and Entomology, Ahmadu Bello University Zaria for providing the test organism and other technical assistance.

\section{Funding}

This work received no external funding

\section{Conflicts of Interest}

The authors declared no conflict of interest.

\section{References}

1. ILRAD.Annual Report.International Laboratory for Research on Animal Diseases; 1994. Available from: http://www.hdi.handle.net/10568/49926.
2. D'Archivio, S.; Medina, M.; Cosson, A.; Chamond, N.; Rotureau, B.; Minoprio, P. (2011): Genetic engineering of Trypanosoma (Dutonella) vivax and in vitro differentiation under axenic conditions. PLoSNegl. Trop. Dis. 5, e1461.

3. World Health Organization (2019). World Health Organization model list of essential medicines: 21st list 2019. Geneva: World Health Organization. hdl:10665/325771. WHO/MVP/EMP/IAU/2019.06. License: CC BY-NC-SA 3.0 IGO.

3.World Health Organisation (2016). Human African trypanosomiasis (sleeping sickness): epidemiological update. Weekly Epidemiology Rec.; 81: 71 - 80.

4. Diall O, Cecchi G, Wanda G, Argiles-Herrero R, Vreysen MJB, Cattoli $G$, et al. Developing a progressive control pathway for African animal trypanosomosis. Trends Parasitology. 2017;33: 499509

5. Anene BM, Chima AB, Jibike GI, Anika SM. Prevalence of trypanosomiasis in Zebu at Obudu ranch- a tsetse free zone in Nigeria. Prev Vet Med. 1991;10: 257-60.

6. Githua, M., Hassanali, A., Keriko J., Murilla, G.,Ndungu, M. and Nyagah, G. (2010). New Antitrypanosomal tetranotriterpenes from Azadirachta indica. African journal of traditional medicine.CAM.; 7: $207-213$

7. Jigam A A, Akanya HO, Dauda BEN, Okogun JO (2010). Polygalloyl tannin isolated from the roots of Acacia nilotica Del. (Leguminoseae) is effective against Plasmodium berghei in mice. Journal of Medicinal Plants Resources, 4(12): 1169-1175.

8. Abdulhamid, A Y. U. Dabai and Amar Mohamed Ismail (2019): Preliminary phytochemical screening and Antibacterial properties of crude leaves extract and fractions of Acacia nilotica (Linn.).World Journal of Pharmaceutical Research, (7):8-18.

9. Monier MAE. Traditional medicinal plants of Nigeria: an overview. Agriculture and Biology Journal of North America, 2016; 7(5): 220-247.

10. Singh R, Singh B, Singh S, Kumar N, Kumar $\mathrm{S}$, Arora S. Umbelliferone - An antioxidant isolated from Acacia nilotica (L.) Willd. Ex. Del. Food Chemistry $2015 ; 120: 825-830$

11. Evans 1996. Phytochemical methods. In. A Guide to modern techniques of plants analysis ( $3^{\text {rd }}$ edition) chapman and Hall Ltd, London: 40-137.

12. Chechet GD, Yahaya, J and Nok A.J.In vitro and In vivo anti- trypanosomal potentials of Afrormosia laxiflora and khaya senegalensis against Trypanosoma brucei brucei.Nigerian Veterinary Journal, 2018; 39 (3): 269-284. 
13. Ogbadoyi EO, Garba MH, Kabiru AY, Mann A, Okogun JI. (2011): Therapeutic evaluation of Acacia nilotica (Linn) stem bark extract in experimental African trypanosomiasis: International Journal of Applied Research in Natural Product: Vol. 4 (2), pp. 11-18.

14. Jatau, I.D and Tsok-Nwok, V.V (2018): Antitrupanosoma effect of methanol fruit pod extract of Acacia nilotica (Linn) in acute Trypanosoma brucei brucei infection in Wistar rats. Nigerian journal of Animal production.44(5)29-33.

15. Herbert W.J, Lumsden W.H.R. 1976:Trypanosoma brucei: A rapid "matching" method for estimating the host parasitemia. Experimental parasitology.,40:427431.

16.Teka, F., Getachew, T. andWorkineh, S. (2014). Evaluation of in vivo antitrypanosomal activity of crude extracts of Artemisia abyssinica against a Trypanosoma congolense isolate. BMC Complementary and Alternative Medicine, 14:117.

17.Ververidis F, Trantas E, Douglas C, Vollmer G, Kretzschmar G, Panopoulos N. Biotechnology of flavonoids and other phenylpropanoid-derived natural products. Part 1: Chemical diversity, impacts on plant biology and human health. Biotechnology Journal. 2007; 2: 10-12

18. Cowan MM. Plant products as antimicrobial agents. Clinical Microbiology Review., 1999; 12: 564 -582 .

19. Anyam JV, Daikwo PE, Ungogo MA, Nweze NE, Igoli NP, Gray AI, De Koning HP and Igoli JO :(2021) Two New Antiprotozoal Diterpenes From the Roots of Acacia nilotica.FrontierChemistry. 9:624741.doi: 10.3389/fchem.2021.624741

20. Atawodi, S. E., Bulus, T., Ibraham, S., Ameh, D. A., Nok, A. J., Mamman, M. and Galadima, M. (2011). In vitro trypanocidal effect of methanolic extract of some Nigerian Savannah plants. African Journal of Biotechology.; 2: $317-321$.

21. D'ieteren, G. D.M., Authié, E.,Wissocq, N. and Murray, M.(1998). Trypano-tolerance an option for sustainable livestock production in areas at risk from trypanosomiasis. Revueb scientifique et technique (International Office of Epizootics)17:154-175.
22. El-Mahmood AM, Doughari JH, Chanji FJ. (2008) In vitro antibacterial activities of extracts of Nauclea latifolia and Daniell aoliveri. Sci. Res. Essay, 2008; 3: 102-105

23. El-Tahir A, Satti GM, Khalid SA (1999). Antiplasmodial activity of selected sudanese medicinal plants with emphasis on Acacia nilotica. Phytother. Res., 13: 474-478.

24. Kirsch, G. G. M., Kong, A., Wright, D. and Kaminsky, R. (2000). Application of a New Expert System for the Structure Elucidation of Natural Products from Their 1D and 2D NMR Data. J. Nat. Prod.; 63: 825.

\section{Submit your article to AROC JOURNALS -AROC in Pharmaceutical and Biotechnology -AROC in Agriculture -AROC in Food and Nutrition -AROC in Natural Products Research -BIOMED Natural and Applied Science Via https://arocjournal.com/}

Copyright (c) 2022 Goronyo et al. This is an open access article distributed under the terms and conditions of the Creative Commons Attribution License (CC BY) which allowed unrestricted download, distribution and reused as long as the original authors are properly cited. 